Pediat. Res. 4: 7-13 (1970)

Cardiac output

developmental physiology

glomerular filtration rate

kidney newborn

pulmonary resistance renal hemodynamics

\title{
Maturational Changes in Renal Blood Flow in Piglets
}

\author{
Alan B. Gruskin ${ }^{[46]}$, Ghester M. Edelmann, Jr. and Stanley Yuan \\ Department of Pediatrics, Albert Einstein College of Medicine, Bronx, New York, USA
}

\begin{abstract}
Extract
Cardiac output, renal blood flow, and intrinsic renal vascular resistance were measured in piglets ranging in age from $6 \mathrm{~h}$ to 45 days. During this period of time the mean cardiac output increased from 0.9 to 6.5 liters $/ \mathrm{min} / \mathrm{m}^{2}$, the mean renal blood flow increased from 0.043 to 0.76 liters $/ \mathrm{min} / \mathrm{m}^{2}$, and intrinsic renal vascular resistance dropped from 1,605 to $138 \mathrm{~mm} \mathrm{Hg} / \mathrm{liter} / \mathrm{min} / \mathrm{m}^{2}$. These data demonstrate that the large increase in renal blood flow in the pig during the first 6 weeks of life was due to both an increase in cardiac output as well as a decrease in renal vascular resistance. By 6 weeks of age, cardiac output was at adult levels. Since in the adult pig the kidney receives $20 \%$ of the cardiac output, increases in renal blood flow beyond 6 weeks of age must result from further decreases in renal vascular resistance.
\end{abstract}

\section{Speculation}

In the human infant, cardiac index is comparable to values observed in the adult. It appears, therefore, that the entire increase in renal blood flow observed during year 1 of life is due to steadily decreasing renal vascular resistance. Since glomerular filtration rate is modified by the relative resistances in the glomerular afferent and efferent arterioles, the parallel increases in filtration rate during infancy may be related to the same mechanism.

\section{Introduction}

Numerous studies have shown that renal blood flow (RBF), as estimated from hematocrit and clearance of $p$-aminohippurate $\left(\mathrm{C}_{\mathrm{PAH}}\right)$, is low immediately after birth and increases steadily during year 1 of life. In infants who were studied during the first $12 \mathrm{~h}$ of life [23] and whose cords had been clamped either within $5 \mathrm{sec}$ after birth or when the arterial pulsations of the cord had stopped, RBF, calculated as $\mathrm{C}_{\mathrm{PAH}} \div$ (1-venous hematocrit), averaged 142 and $259 \mathrm{ml} / \mathrm{min} / 1.73 \mathrm{~m}^{2}$, respectively. Although measurements of renal extraction of PAH were not performed in this study, investigations [4] indicate that PAH clearance underesti- mates renal plasma flow by not more than $30-40 \%$. Rates of flow reach mature levels $(1,200 \mathrm{ml} / \mathrm{min} / 1.73$ $\left.\mathrm{m}^{2}\right)$ by 1 year of age $[2,24,28]$.

Data available in other species, including dog (unpublished observations in this laboratory), sheep [1], and pig [22], suggest that an increase in $R B F$ is a maturational phenomenon common to mammals. In addition, subsequent to birth there is a progressive increase in glomerular filtration rate (GFR), mature values being reached, as with $\mathrm{C}_{\mathrm{PAH}}$, near the end of year 1. Little is known, however, concerning the control of GFR and RBF during this period.

Factors influencing renal blood flow include cardiac output, renal perfusion pressure, intrinsic renal vascu- 
lar resistance, and the vascular resistance of the kidney relative to that of the remainder of the body. The present studies were undertaken to define the relation of these factors to the changes in renal blood flow that occur during the neonatal period in piglets. On the basis of these studies and other available data, a hypothesis is suggested to explain the postnatal increase in renal blood flow and glomerular filtration rate in infants [14].

\section{Materials and Methods}

Forty-one unanesthetized piglets, ranging in age from $6 \mathrm{~h}$ to 45 days, were studied. Under local anesthesia ( $2 \%$ lidocaine), the left external jugular vein and internal carotid artery were isolated, and polyethylene catheters were passed with monitoring of pressure into the left ventricle and right ventricle or pulmonary artery. A known count of scandium-46 nuclide microspheres [35], $50 \pm 5 \mu$ in diameter, was then injected into the left ventricle. Upon completion of the injection of the spheres, the position of the left ventricular catheter was verified by the demonstration of a left ventricular pressure curve and the catheter was withdrawn into the ascending aorta. Sequential CardioGreen [36] dye dilution measurements of cardiac output were then performed. Multiple measurements of arterial and venous pressures were made throughout the study. Upon completion of the study, the piglet was killed and the kidneys removed for counting.

A stock supply of scandium- 46 spheres was made by suspending $2 \mathrm{mGi}$ of the spheres in $25 \mathrm{ml}$ of dextran, with 1 drop of polyoxyethylene sorbitan monooleate (Tween 20) [37] added to the solution to prevent clumping of spheres. Prior to injection into the piglet, sufficient spheres to provide about 50,000-200,000 cpm were drawn into a $2-\mathrm{ml}$ disposable plastic syringe. The remainder of the syringe was filled with $0.9 \%$ saline and the count rate determined again. After injecting the spheres into the left ventricle, the syringe was refilled with saline in order to maintain geometry, and counted again. The amount delivered to the animal equalled the count rate of the injection syringe prior to injection minus the count rate of the same syringe after injection. It has been demonstrated that these microspheres distribute in accordance with blood flow, become trapped in the various organs during their primary circulation, and do not recirculate [29].

After the kidneys were removed from the body, they were sliced into sections and placed in the bottom $5 \mathrm{~cm}$ of glass counting tubes. Counting was done by gamma counting with pulse height analysis [38]; the range counted was $600-800 \mathrm{kev}$. Count rates were more than twice background, and the total count per minute per specimen was a minimum of 5,000 . The count rate was corrected for background prior to subsequent calculations.

Determination of cardiac output was performed by injection of $0.2-0.5 \mathrm{ml}$ of Cardio-Green solution containing $2.5 \mathrm{mg}$ of dye $/ \mathrm{ml}$ into the right ventricle. After injection of the dye, the right ventricular catheter was flushed with $0.3-0.5 \mathrm{ml}$ of $0.9 \%$ saline. Sampling from the ascending aorta was accomplished at a rate of 10 $\mathrm{ml} / \mathrm{min}$ by the use of a constant speed withdrawal pump [39]. The blood was withdrawn through a cuvette densitometer [40] capable of background dye suppression, and the calibration and the dye curve inscribed on a direct writing recorder [41] at a speed of $10 \mathrm{~mm} / \mathrm{sec}$. Following completion of the dye curve, all blood was reinfused into the piglet prior to a repeat determination.

The method of HamiLton et al. [15] was used for the calculation of cardiac output. At least 4 points were used to obtain the down slope of each curve. Repeat measurements of cardiac output agreed within $15 \%$ and the average values were used for the calculation of RBF.

Pressure measurements were obtained by means of P23 $\mathrm{Db}$ pressure transducers and were transcribed on a recorder. The zero reference point utilized was the midthorax. In the calculations, it was assumed that mean aortic pressure was equal to mean renal arterial pressure, and that mean inferior vena cava pressure was equal to mean renal vein pressure. The following calculations were performed: 1) the fraction of total cardiac output to the kidney was taken as the ratio of kidney counts to total body counts; 2) actual total renal blood flow was determined as the product of the cardiac output and the fraction of total cardiac output to the kidney; 3) relative renal vascular resistance was taken as the ratio of total renal blood flow to the total cardiac output, which is the same as the ratio of total kidney count to total body count; 4) actual renal vascular resistance was calculated as the pressure drop across the kidney divided by the renal blood flow.

Compared with the PAH clearance technique, the methodology used to determine renal blood flow avoided either making assumptions concerning the extraction ratio or performing renal vein catheterization to determine the extraction ratio. The present technique does not require general anesthesia, major surgery, or collection of urine. RudolPh and Heymann [29] have shown, as determined from repeated injections of microspheres, that fractional distribution varied less than $5 \%$. The overall error in the method thus may be as great as $20 \%, 15 \%$ being related to the use of the indicator dilution technique for determining cardiac output, and $5 \%$ to the distribution of the microspheres. The magnitude of the changes observed was much greater than the estimated error of the method. 


\section{Results}

In order to compare animals of varying size and age, the results have been related, with the exception of pressure measurements and fractional renal blood flow, to $1 \mathrm{~m}^{2}$ of body surface area (BSA). In the figures, each point represents the mean of values from a single piglet. In two piglets, technical difficulties prevented measurement of cardiac output. For these two animals only, the data for aortic pressure and fractional cardiac output to the kidney are shown.

Age-related Changes in RBF, Cardiac Index, and Relative Renal Resistance

In figure $1, \mathrm{RBF} / \mathrm{m}^{2} \mathrm{BSA}$ was plotted as a function of age. No differences related to age were noted in animals less than $24 \mathrm{~h}$ old. The RBF increased progressively from an average value of $0.043 \mathrm{liters} / \mathrm{min} / \mathrm{m}^{2}$ during the first $24 \mathrm{~h}$ of life to 0.76 liters $/ \mathrm{min} / \mathrm{m}^{2}$ by

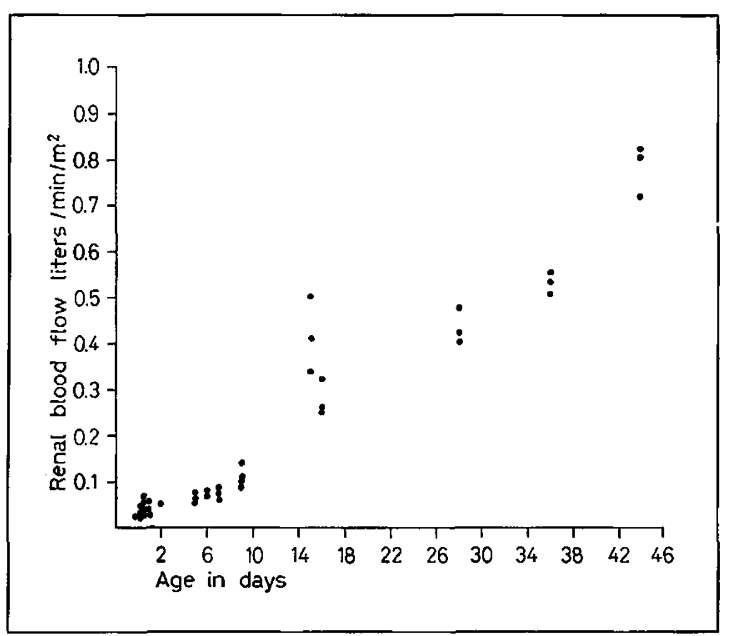

Fig. 1. Changes in renal blood flow with age.

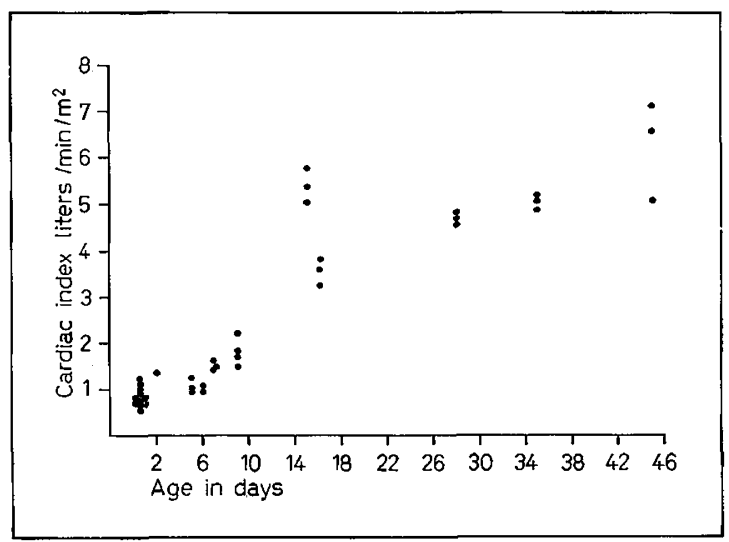

Fig. 2. Changes in cardiac index with age.
45 days of age. During this period, cardiac index, shown in figure 2, increased 7.2 times, from 0.9 to 6.5 liters $/ \mathrm{min} / \mathrm{m}^{2}$.

Since RBF increased approximately 18.2 times its initial value while cardiac output increased only 7.2 times, the changes in cardiac output alone cannot be the sole explanation for the increase in RBF; a decrease in relative renal resistance also must have occurred. In figure 3, fractional cardiac output to the kidney was plotted against age, increasing from an average of $4.8 \%$ during day 1 of life to $12.1 \%$ by day 45 . It can be seen that by 2 weeks of age the lowest value

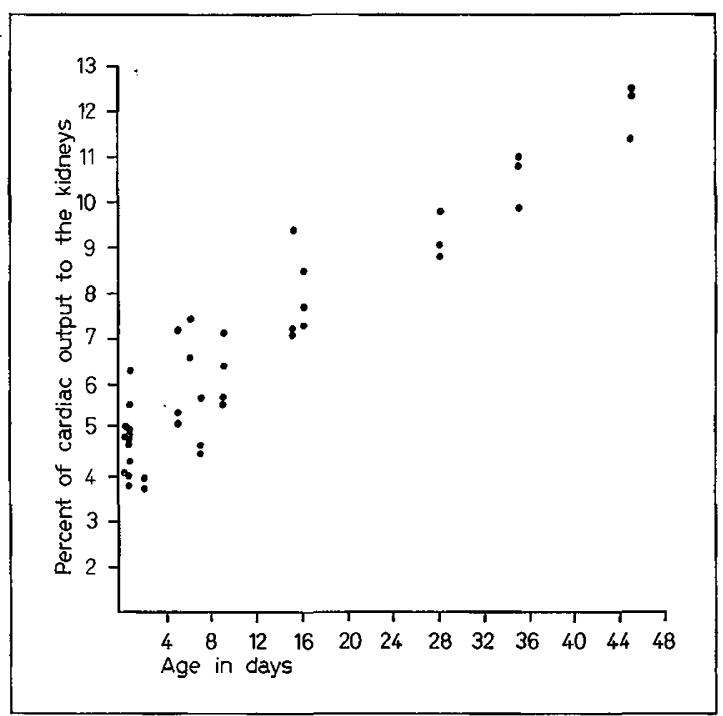

Fig. 3. Changes in fraction of cardiac output perfusing the kidney with age.

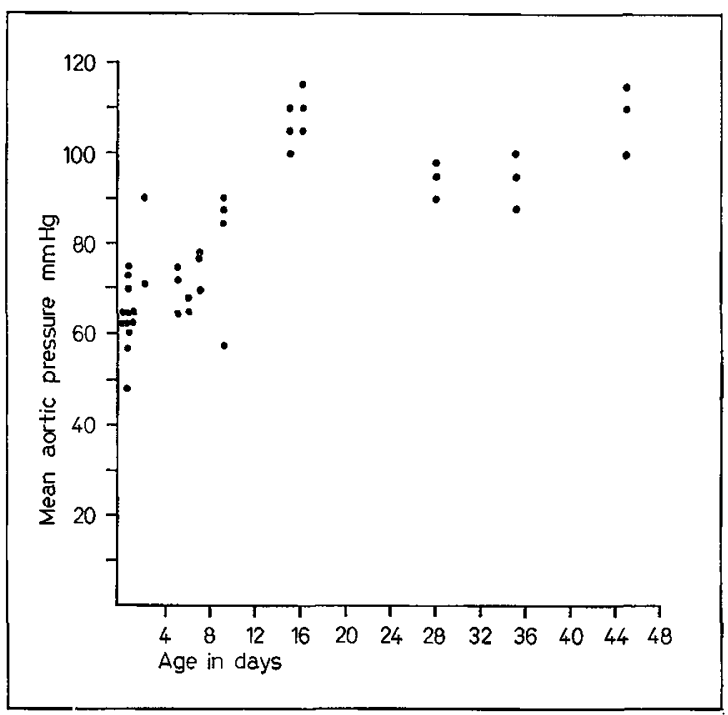

Fig.4. Changes in mean aortic pressure with age. 


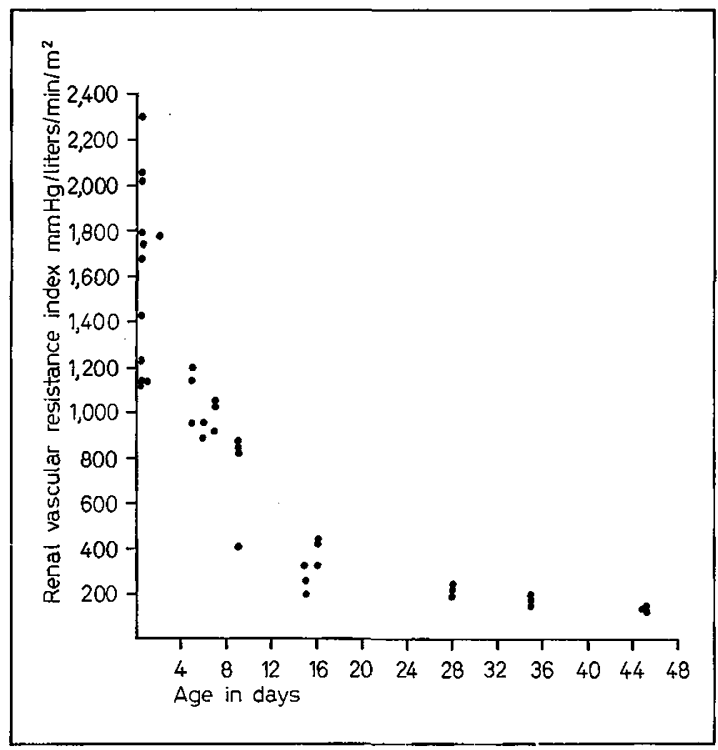

Fig. 5. Changes in renal vascular resistance index with age.

for fractional cardiac output to the kidney was greater than the highest value found during the first $24 \mathrm{~h}$ of life.

Age-related Changes in Aortic Pressure and Actual Renal Vascular Resistance

Mean aortic pressure increased from an average value of $64 \mathrm{~mm} \mathrm{Hg}$ during day 1 of life to an average of $108 \mathrm{~mm} \mathrm{Hg}$ by day 45, as shown in figure 4. Changes in organal flow, however, cannot be attributed to an increase in perfusion pressure, unless there is a change in relative organal resistance, since all major organs are perfused with approximately the same arterial pressure. Figure 5, in which actual renal vascular resistance index is plotted against age, shows that over the period studied, actual renal vascular resistance index dropped $86 \%$, from an average value of 1,605 $\mathrm{mm} \mathrm{Hg} / \mathrm{liter} / \mathrm{min} / \mathrm{m}^{2}$ to $138 \mathrm{~mm} \mathrm{Hg} / \mathrm{liter} / \mathrm{min} / \mathrm{m}^{2}$.

\section{Discussion}

\section{Factors Determining Renal Blood Flow}

Total RBF is determined by the level of cardiac output and the fraction of the cardiac output perfusing the kidneys. The latter depends upon the resistance of the kidney relative to the remainder of the body and the level of the arterial pressure. During the first 45 days of life of the piglet, $\mathrm{RBF} / \mathrm{m}^{2} \mathrm{BSA}$ increased 18 times its initial value, as a result of a 7.2-fold increase in cardiac index and a 2.5-fold increase in fractional flow to the kidney.
No further increase in cardiac index with age occurs in the pig. The average cardiac index of 5.1 liters $/ \mathrm{min}$ observed in piglets 14-45 days old was similar to values obtained in adult swine by indicator dilution techniques [30]. Using the data available for $\mathrm{G}_{\mathrm{PAH}}$ and cardiac output in mature swine, it appears that the mature kidney receives between 20 and $30 \%$ of the cardiac output. Increases in $R B F$ beyond 45 days of age thus appear to be a consequence of further decreases in relative renal resistance. That the increase in $\mathrm{RBF}$ must be independent of changes in arterial pressure is apparent since all organs in the body can be considered to be in parallel and are perfused at approximately the same level of arterial pressure. Thus, for given levels of arterial pressure and cardiac output, changes in organal blood flow occur only as a result of changes in organal resistance. In these studies, the age-related increase in $\mathrm{RBF}$ was reflected in an $86 \%$ drop in actual renal vascular resistance index.

The present investigations do not permit indentification of the region within the kidney where the increase in RBF occurs. Since the cortex receives most of the blood in the mature kidney, it may be reasonable to assume that the greater part of the postnatal increase in RBF occurs in this region. Studies in the developing rat [16] and the puppy [18, 19], involving measurements of renal extraction of $\mathrm{PAH}$, have demonstrated a relative preponderance of medullary blood flow, with a shift to cortical flow with advancing age. In the pig, the increase after birth in the number of cortical glomeruli [32] may explain part of the increase in blood flow. Other species, including man, however, do not develop new glomeruli following birth [25].

\section{Fetal and Neonatal Changes in RBF and Pulmonary Blood Flow}

Toward the end of gestation and subsequent to birth, the changes observed in pulmonary and renal hemodynamics are similar. In fetal life the placenta assumes excretory and respiratory functions as well as the maintenance of body fluid homeostasis. The placenta receives a major portion of the cardiac output while both the fetal lung and kidney [29] receive a relatively small proportion. A higher rate of blood flow to the lungs toward the end of gestation is prevented by a rise in pulmonary vascular resistance [6]. Measurements of renal vascular resistance in near-term fetal lambs, as in piglets, are reported as being high [31].

After birth both the kidneys and lungs must assume their respective physiologic roles. Coincident with this role there is an increase in both pulmonary and renal blood flow, although these occur at different rates. Measurements of pulmonary vascular resistance in 
both humans [8] and experimental animals [5] demonstrate age-related decreases. The present studies demonstrated a similar decrease in renal vascular resistance. The pattern of change in vascular resistance of the kidney with age was similar to that of the lung, in that there was a rapid initial fall immediately following birth followed by a slower subsequent fall.

Available data suggest that a drop in renal vascular resistance occurs in human infants after birth. JÄYKKÄ [17] has demonstrated that in the fetus turgid cells of the juxtaglomerular apparatus in the walls of the afferent arterioles obstruct the flow of blood into the glomeruli. Following birth, in the functioning kidney, these cells disappear, permitting the arterioles to open up. Anatomical studies of arteriolar wall-to-lumen ratios, which may reflect the degree of vascular resistance, have shown that subsequent to birth a progressive vasodilatation of both pulmonary $[21,33]$ and renal [21] arterioles occur, although at different rates.

\section{Age-related Changes in RBF in Human Infants}

Published data suggest that changes similar to those observed in the present studies occur in human infants. The $\mathrm{C}_{\mathrm{PAH}}$ increases five to six times during year 1 of life [2-4, 6]. Calcagno and Rubin [4] found that renal extraction of PAH in the young infant may be as low as $50 \%$, suggesting that clearance of $\mathrm{PAH}$ markedly underestimates true renal plasma flow or the value of renal blood flow calculated from it. Nevertheless, there is probably at least a threefold increase in renal blood flow relative to either body surface area or kidney size during year 1 of life.

Values for cardiac index in newborn infants range from 2.5 to 4.0 liters $/ \mathrm{min} / \mathrm{m}^{2}[11,26]$; in the adult the average value for cardiac index is 3.12 liters $/ \mathrm{min} / \mathrm{m}^{2}$ [7]. Mean systemic arterial pressure increases from approximately 60 to $70 \mathrm{~mm} \mathrm{Hg}[20,34]$ in the immediate newborn period, to $100 \mathrm{~mm} \mathrm{Hg}$ at puberty [12]. Thus, it appears likely that neither changes in cardiac output nor changes in arterial pressure can explain fully the postnatal increase in RBF, but that the major age-related hemodynamic change is brought about by a drop in both relative and intrinsic renal vascular resistance. Calculations of fractional cardiac output to the kidney suggest that in the human neonate this organ receives approximately $5-6 \%$ of the cardiac output, in comparison to the adult in whom it receives $15-25 \%$ [3].

\section{Relation of Changes in $R B F$ to Changes in $G F R$}

The rate of formation of glomerular filtrate depends upon the mean glomerular capillary pressure, which is a consequence of the pressure gradient between the renal afferent and efferent arterioles, and the bulk flow of plasma over the filtering surface of the glomer- ulus. Increases in GFR with age may be the result of increased intraglomerular capillary pressure (assuming that glomerular oncotic pressure remains constant), anatomical changes, or increased RBF.

Although the pressure drop across the glomerulus may be lower than assumed on the basis of mean renal arterial and venous pressures, because of differences in either afferent or efferent arteriolar resistance, the rise in systemic pressure subsequent to birth is not great enough by itself to explain the increases in GFR that have been observed, although it may play some role.

Obstruction to the formation of glomerular filtrate by cuboidal epithelium has been suggested as a limiting factor. The cuboidal epithelium, however, assumes a flat appearance following birth $[17,27]$ while GFR is still increasing.

An increase in GFR might relate to an increase in the surface area available for filtration, from either the formation of new glomeruli or the formation of new capillaries within existing glomeruli, or both. The cortical nephrogenic zone in the piglet thus may contribute to the increase in the GFR with age. Other species, including man, however, do not form new glomeruli subsequent to birth, yet the same phenomenon of an increasing GFR is observed. In man, the diameter of the neonatal glomerulus is more than one-third that of the adult [10], whereas GFR is approximately onefifteenth to one-twentieth of adult values. Although an increased number of glomerular capillaries is observed with age, the amount of new filtering surface is probably not great enough to explain the increase in GFR. This suggests that the filtering surface is not the limiting factor in the rate of formation of glomerular filtrate [9]. Probably of some importance, however, is the increased glomerular permeability that is observed with increasing age [13]. In summary, therefore, although age-related increases in GFR appear to depend to a major extent upon increased blood flow though the glomerular capillaries, changes in perfusion pressure, glomerular size, and capillary permeability all probably contribute to some degree.

\section{Summary}

Maturational changes in the hemodynamic factors influencing renal blood flow have been measured in 41 piglets ranging in age from $6 \mathrm{~h}$ to 45 days. The four physiologic variables examined were cardiac output, mean aortic pressure, relative renal vascular resistance (defined as the fraction of cardiac output perfusing the kidney), and intrinsic renal vascular resistance. By day 45, renal blood flow increased 18.2 time its initial value, cardiac index increased 7.2 times, and 
arterial pressure increased 1.8 times. Relative renal resistance decreased to $40 \%$ and the intrinsic renal vascular resistance dropped to $86 \%$ of the initial values. These data demonstrate that, in the pig, large increases in renal blood flow that occur during the first 6 weeks of life are the result of both an increase in cardiac output as well as a decrease in relative renal vascular resistance.

A review of available data suggests that similar hemodynamic changes occur subsequent to birth in human infants. Since the change in cardiac index from birth to maturity is less marked in infants than in pigs, it appears likely that in infants the major hemodynamic factor causing an increase in renal blood flow with age is a decrease in relative renal vascular resistance.

\section{References and Notes}

1. Alexander, D.P. and Nixon, D.A.: The foetal kidney. Brit. med. Bull. 17: 112-117 (1961).

2. Barnetr, H.L. and Vesterdal, J.: The physiologic and clinical significance of immaturity of kidney function in young infants. J. Pediat. 42: 99-119 (1953).

3. Bolomey, A. A.; Michie, A. J.; Mighie, C. ; Breed, E.S.; Schreiner, G.E. and Lauson, H.D.: Simultaneous measurement of effective renal blood flow and cardiac output in resting normal subjects and patients with essential hypertension. J.clin. Invest. 28: 10-17 (1949).

4. Calcagno, P.L. and Rubin, M. I.: Renal extraction of para-aminohippurate in infants and children. J. clin. Invest. 42: 1632-1639 (1963).

5. Cassin, S.; Dawes, G.S.; Mott, J.L.; Ross, B.B. and StRANG, L.B.: The vascular resistance of the foetal and newly ventilated lung of the lamb. J. Physiol., Lond. 171: 61-79 (1964).

6. Cassin, S.; Dawes, G.S. and Ross, B.B.: Pulmonary blood flow and vascular resistance in immature foetal lambs. J. Physiol., Lond. 171: 80-89 (1964).

7. Cournand, A.; Riley, R. L.; Breed, E. S. ; BaldWIN, E. DE F. and Righards, D.W., Jr.: Measurement of cardiac output in man using the technique of catheterization of the right auricle or ventricle. J.clin. Invest. 24: 106-116 (1945).

8. Dawes, G.S.: Pulmonary circulation in the foetus and newborn. Brit.med. Bull. 22: 61-65 (1966).

9. Edelmann, C.M., Jr.: Maturation of the neonatal kidney. Proc.3rd int. Congr. Nephrology, vol.3, pp. 1-12 (Karger, Basel/New York 1967).

10. Fetterman, G.H.; Shuplock, N.A.; Phillpp, F.J. and GreGG, H.S.: The growth and matura- tion of human glomeruli and proximal convolutions from term to adulthood. Studies by microdissection. Pediatrics 35: 601-619 (1965).

11. Gessner, I.; Krovetz, L.J.; Benson, R.W.; Prystowsky, H.; Stenger, V. and Ertzman, D.V.: Hemodynamic adaptations in the newborn infant. Pediatrics 36: 752-762 (1965).

12. Graham, A.W.; Hines, E. A., Jr. and Gage, R. P.: Blood pressure in children between the ages of five and sixteen years. Amer. J. Dis. Child. 69: 203-207 (1945).

13. Grotte, G.; Artursson, G. and Malmberg, P.: Maturation of kidney function. Proc. 12th int. Congr. Pediatrics, Mexico City, vol.3, p. 32 (Impresiones Modernas, Mexico 1968).

14. Gruskin, A.B.; Edelmann, G.M., Jr. and Yuan, S. : Maturational changes in renal blood flow. Fed. Proc. 27: 630 (1968).

15. Hamilton, W.F.; Moore, J.W.; Kinsman, J.M. and Spruling, R.G.: Studies on the circulation. IV. Further analysis of the injection method, and of changes in hemodynamics under physiological and pathological conditions. Amer. J. Physiol. 99: 534-551 (1932).

16. Horster, M. and Lewy, J. E.: Influence of maturation on GFR and RBF in the rat kidney (abstract). 39th Ann. Meet. Soc. Pediatric Research, Atlantic City, N.J., May 2, 3; p. 117 (1969).

17. J̈̈чкKё, S.: The problem of dormant fetal organs: the kidneys, lungs and the gut. Biol.neonat. 3: 343-356 (1961).

18. Lubbe, R.J. and Kleinman, L. I.: Renal function in newborn puppies (abstract). 39th Ann. Meet. Soc. Pediatric Research, Atlantic City, N.J., May 2, 3; p. 119 (1969).

19. Moore, E. S.; Satrasook, S. S.; Fine, B. P.; Katz, M.C. and EDELMANN, G.M., Jr.: PAH extraction in puppies (abstract). 39th. Ann. Meet. Soc. Pediatric Research, Atlantic City, N.J., May 2, 3; p. 119 (1969).

20. Morse, R.L.; Brownell, G.L. and Currens, J.H.: The blood pressure of newborn infants: Indirect determination by an automatic blood pressure recorder in 20 infants. Pediatrics 25: 50-53 (1960).

21. NAEye, R.L.: Development of systemic and pulmonary arteries from birth through early childhood. Biol. neonat. 10: 8-16 (1966).

22. Nielsen, T.W.; MaAske, G. A. and Booth, N.H.: Some comparative aspects of porcine renal function; in: L.K.Bustad and R.O.McGlellaN: Swine in biomedical research, pp.530-536 (Frayn, Seattle 1966).

23. $\mathrm{OH}$, W.; OH, M.A. and Lind, J.: Renal function and blood volume in newborn infant related to 
placental transfusion. Acta pediat. scand. 55: 197-210 (1966).

24. Prrss, R.F.: Physiology of the kidney and body fluids; 2nd ed., pp. 144-161 (Year Book, Chicago 1968).

25. Potter, E.L. and Thuerstein, S.T.: Glomerular development in the kidney as an index of foetal maturity. J.Pediat. 22: 695-706 (1943).

26. Prec, K. J. and Cassels, D. E.: Dye dilution curves and cardiac output in newborn infants. Circulation 11: 789-798 (1955).

27. Rrodin, J.A.G.: Structure of the kidney; in: M.B.Strauss and L.G.Welt: Diseases of the kidney, pp. 1-29 (Little, Brown, Boston 1963).

28. Rubin, M.X.; BRuCK, E. and RAPOPORT, M.: Maturation of renal function in childhood. Clearance studies. J. clin. Invest. 28: 1144-1 162 (1949).

29. Rudolph, A. M. and Heymann, M.A.: The circulation of the fetus in utero. Circulat. Res. 21: 163-184 (1967).

30. Stone, H. L. and SAwyer, D. C.: Cardiac output and related measurements in unanesthetized miniature swine; in: L.K. BusTAD and R. O. MCGLELLAN: Swine in biomedical research, pp.414-418 (Frayn, Seattle 1966).

31. Vaughn, D.; Kirschbaum, T.H.; Bersentes, T.; Dilts, P.V., Jr. and Assali, N.S. : Fetal and neonatal response to acid loading in the sheep. J. appl. Physiol. 24: 135-141 (1968).

32. Vogh, B. and Cassin, S.: Stop flow analysis of renal function in newborn and maturing swine. Biol.neonat. 10: 153-165 (1966).
33. Wagenvoort, L.A.; Neufeld, H.N. and EDWARDS, J.E.: The structure of the pulmonary arterial tree in fetal and early postnatal life. Lab. Invest. 10: 751-762 (1961).

34. Young, M.: Blood pressure in the newborn baby. Brit.med. Bull. 17: 154-159 (1961).

35. Nuclear Products Division of the Minnesota Mining and Manufacturing Company.

36. Cardio-Green obtained from Hynson, Westcott, and Dunning, Baltimore.

37. Tween 20 obtained from Fisher Scientific Company, Springfield, NJ.

38. Picker Magna Well with Spectro Scaler, model IIIA, Picker Nuclear, White Plains, NY.

39. Harvard Apparatus Company, Inc., Millis, MA.

40. Model X-300, Waters Associates, Framingham, MA.

41. Polygraph recorder, Grass Medical Instruments, Quincy, MA.

42. The authors thank Mr. Herbert Parker for his valuable technical assistance.

43. Presented in part at the annual meeting of The American Physiological Society, April 19, 1968.

44. Dr. Gruskin was a postdoctoral research fellow, Public Health Service Training Grant no. 2T1-5532-06.

45. Supported in part by Public Health Service Research Grant no. HE 08378-04.

46. Requests for reprints should be addressed to: ALAN B. Gruskin, M.D., St. Christopher's Hospital for Sick Children, 2600 N. Lawrence Street, Philadelphia, PA, 19133 (USA). Tabular material supplying all data is available with reprints.

47. Accepted for publication September 9, 1969. 